\title{
Budging beliefs, nudging behaviour
}

\author{
Oliver P. Hauser ${ }^{1} \cdot$ Francesca Gino $^{2} \cdot$ Michael I. Norton ${ }^{2}$
}

Published online: 13 March 2019

(C) The Author(s) 2019

\begin{abstract}
Nudges have become a popular tool for behaviour change; but, some interventions fail to replicate, even when the identical, previously successful intervention is used. One cause of this problem is that people default to using some of or all of the previously-successful existing nudges for any problem-the "kitchen sink" approach. We argue that the success of an intervention depends on understanding people's current behaviour and beliefs to ensure that any nudge will actually "budge" them from their current beliefs. We introduce the Beliefs-Barriers-Context model, with three components: understanding beliefs, barriers, and context to change behaviour through a budge. Designing a budge has the goal of identifying the psychological mechanism that drives a target behaviour, focusing on the psychology of the target population before attempting to change that behaviour. In contrast to the "kitchen sink" approach, budges are best complemented with mechanism experiments to identify what undergirds behaviour change. Moving away from simply nudging behaviour to budging minds - by understanding beliefs, barriers and context—has the potential to inform both the successes and failures of behavioural interventions.
\end{abstract}

Keywords Nudges $\cdot$ Budges $\cdot$ Interventions $\cdot$ Behavioural insights $\cdot$ Behavioural science

Experiments sometimes fail to replicate; while there are many reasons for such failures, of course, we focus on one reason that has become particularly important but has also been underappreciated amidst the rise of field experiments conducted by behavioural insights units in governments and organizations: the role of context. For example, in a widely-cited study, (N. J. Goldstein et al. 2008) showed that providing hotel guests in the United States with information that $75 \%$ of hotel guests reused their towels increased reuse. A few years later, however, in a well-powered replication, Bohner and Schlüter (2014) found that providing hotel guests in Germany with

Oliver P. Hauser

O.Hauser@exeter.ac.uk

1 University of Exeter Business School, Exeter EX4 4PU, UK

2 Harvard Business School, Boston, MA 02138, USA 
the same social norm information had no effect. So, do social norms change behaviour? One critical piece of context sheds light on this question: as it turns out, overall towel reuse was quite low in the U.S. sample (in the $30 \%$ and $40 \%$ range) whereas reuse was quite high in the German sample (in the $70 \%$ to $80 \%$ range) ${ }^{1}$ (Bohner and Schlüter 2014). As a result, the $75 \%$ figure represented a dramatically different social norm in the U.S. setting, but simply reflected common practice in the German setting. We use this example of two well-designed and executed experiments for two reasons. First, a social norms intervention (or any nudge) does not simply "work"; the success of such an intervention depends critically on understanding people's current behaviour; and second, efforts to change behaviour (to nudge people) can be informed by careful consideration of the psychology of the underlying population-understanding people's underlying (conscious or unconscious) beliefs in order to ensure that any nudge will actually "budge" them from their current beliefs. In short, we hope to help those wishing to influence a particular behaviour first understand what needs to be budged, which will then help them pick the correct nudge (or nudges) for that context and population, rather than trying nudges at random-or, as is often the case, simply trying all of them (often referred to, informally, as the "kitchen sink" approach). ${ }^{2}$

Behavioural science has taken the academic, policy and business worlds by storm: the notion that small changes in the decision environment can have sizeable effects on behaviour received notable attention in academic and popular outlets (Ariely 2008; Kahneman 2011; Thaler and Sunstein 2008). For example, the Behavioural Insights Team, established in 2010 in the UK Cabinet Office, demonstrated that the timeliness of tax payments can be affected by the mere mention of the level of descriptive social norms (Cialdini 1987; Hallsworth et al. 2016, 2017). Behavioural science units around the world have been established inside governments and corporations, and examples of effective behavioural interventions abound: from reducing

\footnotetext{
1 This obviously implies that the policy problem (e.g. insufficient towel reuse, or even recycling in general) is smaller in Germany than in the US, and it begs the question when and where nudge (or budge) interventions are more effective-when the problem is still large and even small changes can lead to sizeable improvements ("low hanging fruit") or when the policy problem is smaller but the scope is more defined? Future research will need to disentangle those effects, but current scholarship (and anecdotal evidence) might suggest that nudge strategies are more commonly employed for the former case.

${ }^{2}$ We do not want to imply that interventions in practice (e.g. at the many behavioural insights units around the world) are chosen completely at random, or without any consideration. In fact, often behavioural insights units have accumulated substantially amounts of knowledge of which interventions typically work based on their well-powered trials, and they sometimes also pre-test interventions in smaller, online samples before launching them more widely (Halpern 2015).

Unfortunately, however, these insights are often turned into a "kitchen sink" intervention: based on the wealth of prior trials conducted, a "super condition" is constructed which contains multiple nudges which have worked in the past and might work in this situation, too. Sadly, these super conditions sometimes do not work as expected, but it cannot be determined why, given that multiple nudges confound the pathway - and even when they do work, little can be said about why for the same reason. Thus, we argue that even such seemingly practical, empirical approaches fall short on understanding the drivers behind the behaviour (change) and thus make it hard to generalise.

Of note, we think many behavioural insights units are in an excellent position to run highly-powered trials that can be generalised, in part by considering the BBC model and by running "mechanism experiments" which we explain further below.
} 
unethical behaviour by placing signature boxes at the top of forms (Shu et al. 2012) to increasing voter turnout through increased accountability (Rogers et al. 2016) to encouraging people to engage in preventive health measures (Milkman et al. 2011).

These successes suggest that behaviourally-informed approached can be effective and beneficial for society and individuals - especially compared to more costly, alternative policy tools. Indeed, a recent analysis of behavioural compared to traditional policy interventions recommends that governments should further invest in the former as the most cost-effective policy-making tool (Benartzi et al. 2017). At the same time, behavioural interventions can begin to seem like a hodgepodge of interesting but unrelated-or even incoherent-findings, a common problem when academic disciplines are in their infancy. Practitioners routinely rely on published interventions shown to be effective in a university laboratory setting (or, wherever available, in a natural field setting) and implement the same (or very similar) intervention in a field experiment. Most of these early implementations have focused on the practical hurdles to overcome when designing and implementing a behavioural intervention in a randomized field experiment (Hauser et al. 2017; Hauser and Luca 2015; Haynes et al. 2012; List 2006; Podsakoff and Podsakoff 2018), but few have provided decision rules to decide when to use what type of intervention.

Consider the useful "MINDSPACE" and "EAST" frameworks (Dolan et al. 2012; The Behavioural Insights Team 2014), where each letter in each stands for a factor useful to consider in designing an intervention (e.g. "T" in EAST: timeliness of the intervention; " $M$ " in MINDSPACE: the messenger who conveys the intervention). These guides are certainly helpful and will continue to aid practitioners and academics alike but they have also had an unintended side effect. Not all contexts or interventions require "checking off" each letter of the acronym. That is, despite the authors' intentions, many practitioners may use these frameworks to hope to design the "best" interventions by checking off each of the letters in the acronym, believing that more is better. Indeed, people have been shown to have a tendency to "complete" any arbitrary set (e.g. continue working on a task until a pie chart tracking performance is full; see (Barasz et al. 2017)), so checking off every letter may seem like a good idea at the time, but further contributes to the "kitchen sink" approach which is no longer tailored to a specific context or problem. Here we argue for a complementary approach: providing practitioners and academics to a systematic decision rule (the $\mathrm{BBC}$ model) to identify where the problem lies before jumping to designing an intervention based on these acronyms (although we continue to believe that these acro.

\section{The BBC model}

We suggest that one solution to this issue is to move from first thinking which of the existing toolkit of interventions to apply-from social norms (Cialdini and Trost 1998; Hauser et al. 2018; Luca and Hauser 2016) to defaults (Jachimowicz et al. 2019) to anchoring (Furnham and Boo 2011) — to first thinking about the underlying psychology of the target population, and the underlying psychology of the target problem. To oversimply, whereas nudges have tended to focus on changing 
behaviour, we suggest focusing first on the psychological mechanisms likely to be at play in a given population in a given context-one such method could be to first understand minds in order to budge minds, and thereby nudge behaviour. We introduce an adaptive framework for designing effective behavioural nudges, using what we term "budges." We call this framework "Beliefs-Barriers-Context Model" (or "BBC Model") which includes three parameters essential for designing a successful intervention, or budge (see Fig. 1). The three parameters should not be viewed in order of execution or importance, which will differ depending on the context, the population, and the problem.

The first parameter "B" refers to gaining a deep understanding the existing beliefs in the target population. What do people currently believe about the behaviour targeted for change, and are those beliefs accurate or inaccurate? Would changing those beliefs meaningfully affect the subsequent behaviour of interest? For example, past research has found that people hold inaccurate beliefs about the distribution of incomes in the United States, Australia and elsewhere and prefer a much more equal distribution of incomes (Hauser and Norton 2017; Hauser et al. 2016; Kiatpongsan and Norton 2014; Norton and Ariely 2011). It thus seems plausible that correcting those beliefs could affect preferences for redistribution and subsequent behaviour; indeed, (Kuziemko et al. 2015) find that preference for the estate tax are shifted towards more redistribution when people have their inaccurate beliefs corrected.

Note that the beliefs that shape our behaviour need not always be "conscious" or fully accessible to our cognition: since much of our decision-making happens automatically (Kahneman 2011), has been shaped by our experience and repeated actions (Aarts et al. 1998) and even through ecological adaptation (Gigerenzer and Gaissmaier 2011; Goldstein and Gigerenzer 2002), beliefs sometimes form after behaviour has occurred. Indeed, when we make decisions without going through a deliberate thought process, we sometimes retrospectively bring in line our belief system with our actions after they have occurred (Ariely and Norton 2008). For example, many people might subconsciously form beliefs about the extent of income inequality in the country by, for instance, frequently observing their local environment and the extent to which they notice poverty on their way to commute (Sheehy-Skeffington et al. 2016). While they might not consciously be aware of this belief-generation process, those beliefs around poverty likely form an important part of any future (conscious) decision-making process involving taxation or charitable giving. In fact, such subconscious beliefs might lead to a (cognitive) barrier, making the person unwilling to change their behaviour - this brings us to the second parameter of the BBC model.

The second "B" parameter stands for understanding barriers: are there are obvious (or less obvious) barriers in the way of a desired behaviour change? Removing barriers might be the first step to initiate behaviour change. One well-known example of a structural barrier to behaviour change in the context of healthy eating is that unhealthy foods are often placed in highly visible and convenient locations in cafeterias - tempting eaters to indulge. Removing this barrier to healthy eating-by placing foods such as fruits and vegetables in those convenient places-alters eating habits for the better (Thaler and Sunstein 2008). Another example is the availability and ease of access to other opportunities in life: for instance, adolescents 


\section{Understanding}

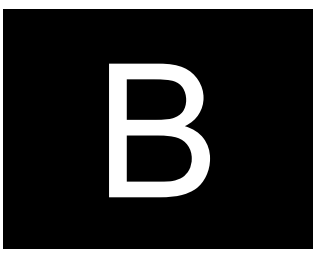

Beliefs:

-What do people believe about the behaviour (change)?

- Are those beliefs accurate or not?

- Would changing those beliefs have an effect?

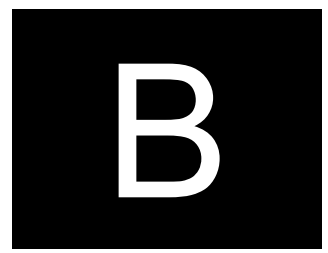

Barriers:

- Are there structural barriers in the way of behaviour change?

- Would removing those barriers enable behaviour change?

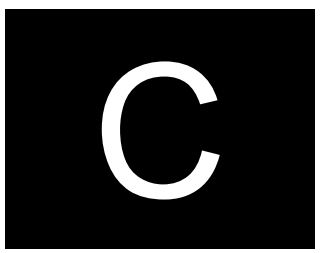

Context:

- Is context similar to past examples?

-What is unique about this context?

- How does the current context shape the appropriateness of the nudge?

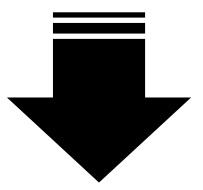

\section{Budge}

- Is derived from understanding beliefs, barriers and context

- Goes beyond checklists and the "kitchen sink" approach

- Identifies one or more mechanisms that affect behavior change

- Is testable through a "mechanism field experiment" which explicitly tests the proposed mechanism that turns the effect on or off

- Informs future interventions by drawing generalizable conclusions

Fig. 1 Designing a budge following the "BBC framework": understanding the pre-existing beliefs about the behaviour, the barriers in the way of a behaviour change, and the context in which the behaviour occurs

in disadvantaged schools in Chicago who were offered minimum-wage jobs for 8 weeks during the summer were less likely to be arrested for violent crimes during and even after the job programme. By removing a structural barrier to entry, youths were able to gain access to, and learn about, the labour market as well as had an opportunity develop social skills, self-efficacy, and perceived control, which had a long-lasting effect on their behaviour (Heller 2014).

The final letter " $C$ " stands for understanding the context: the physical and social setting in which a behaviour takes place. Much has been written in sociology, organisational behaviour, and other social sciences about the importance of context; we 
refer the interested reader to (Cappelli and Sherer 1991; Johns 2006; Mowday and Sutton 1993) for a comprehensive overview. Taking the time to fully understand a given context requires in-depth research, often combining more than one research method including qualitative and inductive methodologies (Chatman and Flynn 2005). Understanding context can radically shift the prior of the likelihood that a given intervention will succeed, and also helps to refine the types of interventions that are most likely to resonate psychologically and result in behaviour change. For instance, evidence that context matters can be illustrated with a highly successful nudge: Shu et al. (2012) demonstrate that placing a signature box at the top of a form highlights an ethical "self-image" and reduced cheating on the form subsequently. This intervention has been replicated in other settings successfully (Congdon and Shankar 2015). However, it has also not replicated in other settings (e.g. (Bhanot 2017a; Kettle et al. 2017)): the moderating factor for this nudge seems to be one type of context, such that signatures that were collected digitally actually increased unethical behaviour, while traditional signatures made by hand decreased unethical behaviour (Chou 2015).

We argue that the BBC model is a first step towards a comprehensive nudge theory. By focusing on beliefs and barriers, the framework is adaptable and general enough to apply for the design of most nudges, turning them into budges. Moreover, considering - and making changes to fit - the context not only increases the feasibility and likely success of an intervention, but also gives theoretical depth to the findings by taking moderating factors into account.

\section{Budges}

Use of the BBC model is intended to result in effective budges. Whereas nudges refer to an intervention that addresses a target behaviour in a specific population in a specific context, budges are meant to help understand the generalisable mechanisms that can then be flexibly adapted to different contexts, behaviours, and populations. The BBC model is well-suited to designing budges because of two of the parameters in the model which target the underlying causes of (lack of) behaviour change: inaccurate beliefs about the behaviour (change) and structural barriers in the way of behaviour change. ${ }^{3}$

We suggest that researchers would benefit greatly by exploring budges through the use of "mechanism experiments" (Ludwig et al. 2011): designing an experiment that explicitly tests the proposed underlying psychological mechanism of the behaviour can demonstrate whether the proposed mechanism is indeed the driver of behaviour. As just one example, even an effective application of social norms that

\footnotetext{
3 Arguably, structural barriers could be viewed as part of each unique context. We do not disagree with this possibility but we think that some barriers have properties that span different contexts, which makes focusing on the barrier separately worthwhile. For instance, a structural barrier to citizens' compliance might be that a required form is complicated to access or hard to find on the government website; whether the context is taxes payments or unemployment claims is likely less important than the crosscontext barrier that the form is hard to locate.
} 
changes behaviour may be due to a number of different causes: it might make people realize that the behaviour is more prevalent than they believed, it might change their sense that the behaviour is endorsed or moral, or may change their belief about how difficult the behaviour is to enact (the barriers). The results of a "mechanism experiment" to test which budge is driving behaviour are insightful in understanding the problem and solution better-even in the case of null findings.

To illustrate the potential of budges, consider again the use of social norms, but in the context of reducing household energy consumption. Social norm interventions have been highly successful, such as in bringing forward late tax payments by showing peers' timely payments (Hallsworth et al. 2017), decreasing the prevalence of unethical behaviour when interacting with government services (Hauser et al. 2018), and reducing energy and water usage by comparing nearby household usage (Allcott 2011; Allcott and Rogers 2014; Bhanot 2017b; Jachimowicz et al. 2018), but have not always worked successfully (e.g. (Silva and John 2017; Verkooijen et al. 2015)). How then can someone interested in changing a given behaviour in a given population in a given context know whether a social norm intervention will be effective in a new setting?

In our experience, choosing which nudge to implement has largely been a matter of the existing evidence that a nudge worked in some other context. That is, if the same nudge has not been applied in the current context, the question quickly becomes: what is the most similar context where it did work? While this may be a useful strategy for some cases, it can also lead to looking very far afield for new context. In contrast, the starting point for budges is different: the question is whether and how a social norm intervention would affect the underlying psychology of the target population. In other words, it works by starting with the individual perspective, moving up to the specific context—rather than take insights from one macrolevel context to another. For example, one predictor of the effectiveness of social norm interventions is that they convey new information to a decision-maker, in particular about their own behaviour relative to that of their peers (Schultz et al. 2007). If a social norm intervention would be likely to manipulate the beliefs people have about their and others behaviour, a social norm nudge might be applicable; if not, it is less likely to be effective.

In the case of household energy consumption, then, at least two relevant "beliefs" question could be asked ${ }^{4}$ : first, do households know how much energy they use and if not, would showing them this information reduce energy usage; and second (and separately from the first question), do they have an accurate belief about what is a "reasonable" amount to use and if they do not, would telling them what others are using change their reference point for what is reasonable? (Note that an alternative question focusing on the barrier component of the BBC model might be to ask if there is a high "barrier" in place to households knowing their energy usage; if this is

\footnotetext{
${ }^{4}$ There are likely other beliefs that could be of interest. For example, (Jachimowicz et al. 2018) show that social norms to reduce energy consumption depends in part on the decision-makers' beliefs about their neighbours' beliefs of the importance on sustainable behaviour ("second-order beliefs"). This suggests that higher-order beliefs can also be influenced to nudge behaviour.
} 
believed to be what needs to be budged, it would likely lead to a different proposed budge. For simplicity, below we focus on the beliefs component.)

These two components to the "beliefs" parameters are related but distinct mechanisms. A typical "kitchen sink" intervention would attempt to affect both beliefs simultaneously, which may increase the likelihood that the nudge will change behaviour but may make the reason why opaque-which can in some cases lead to incorrect inferences about what caused the behaviour change, in turn leading to ineffective future nudges. Instead, both budges can be simply tested by an experiment with four treatments in a two-by-two design: a control condition with no descriptive energy consumption behaviour, one with information about the focal household's energy consumption, one with information about the household's peers' energy consumption, and one with both the household's own and their peers' consumption. If a household's energy consumption alone matters, most of the energy reduction would be observed in the second treatment relative to the first (i.e. the budge is effectively an "information only" treatment without the social component); if it is information about peers that matters (i.e. the intervention is almost exclusively "social"), the third treatment would be more successful; and if both play a role, the fourth treatment would be most successful. At minimum, consideration of the likely beliefs of the population can help in designing an intervention that targets the belief most in need of being changed, while not spending time and money attempting to influence a belief that does not need to be budged..$^{5}$

Why, however, should a policy-maker bother running such a laborious experiment, when it is often virtually costless to add both types of information to the intervention from the start? We believe there are at least two reasons for avoiding the "kitchen sink" approach. On a theoretical basis, it is important to be able to distinguish between the two types of information because it helps understand what drives the effect. As we have argued above, this understanding is key to generalise insights for future trials and interventions (for further discussion, we recommend (Ludwig et al. 2011)'s excellent "mechanism experiment" paper).

But there is also a practical reason for not combining multiple nudges into one intervention lightly: despite the common intuition that "more is better", this does not apply to simply combining nudges to change behaviour for the better-in fact, sometimes "more" can lead to worse outcomes. For instance, the Behavioural Insights Team ran a trial to increase organ donations after the annual car registration process. They varied the message that encouraged citizens to sign up to the organ donor register, relative to a control group without such a message. The best performing message, relative to control, was a message that invoked a sense of reciprocity; among other messages that did well was, yet again, a social norm message that many other people have signed up to the organ donor register. What happened when the

\footnotetext{
5 To the best of our knowledge, a very similar experiment was run by the economists at Opower several years ago and they have continued to run randomised controlled trials to evaluate the performance of social norms in most of their new programmes since then, focusing primarily on the comparison between one's own energy usage and one's own usage plus neighbours' usage (Allcott 2011; Allcott and Rogers 2014; Jachimowicz et al. 2018).
} 
social norm message was further "enhanced" with a nice-looking picture of a group of people, to further emphasise the social aspect of the intervention? Unexpectedly, this intervention significantly reduced sign-ups below the control group sign-up rate (The Behavioural Insights Team 2015).

There are at least two lessons to be learned from this trial. First, combining different nudges will not always yield superior results and may sometimes even backfire. In this case, adding a picture to an otherwise successful intervention did not just cancel out the effect of the effective nudge, but also led to a welfare loss. In other words, while it may be costless to include more nudges in an intervention, it may be costly to do so with regards to the desired outcome.

Second, this trial allows us to disentangle the effect of the social norm-which is good news and close to a mechanism experiment, which we have advocated for. However, it falls short in giving us fill insight into what drives all the results by not also including a condition with just a picture. Without this condition, we cannot tell whether the picture itself would have also led to lower sign up rates, or if the combination of social norms and picture is particularly harmful. To increase our understanding of "what works" and provide insights into future trials where social norms, pictures, and many other nudges may become relevant again, it would have been most useful to have the full experimental design with the missing cell (i.e. picture alone) included.

\section{Limitations}

Budges, we argue, are a form of intervention that systematically considers beliefs, barriers and context to create behaviour change. However, of course, we do not argue that all nudges will need to become "budges"- not every intervention will need to address beliefs, barriers and context, and we do not want the BBC model to become another "check list." Rather, we see this framework as an opportunity to ask whether the researcher or policy-maker has a good grasp of the problem at hand and understands what it might take to change behaviour.

For example, targeting beliefs will be most helpful when the researcher has reason to believe that the target audience has received incorrect information and would change its mind (and potentially behaviour) if they had access to alternative information. For example, information about the prevalence of a prosocial behaviour in the community (e.g. descriptive social norms of others' donation amounts) is an example of shifting beliefs by providing previously hidden information and consequently changing behaviour (Shang and Croson 2009).

There are, however, plenty of cases where this might not be the case- - that is, situations where one's beliefs would not be shifted or updated even if an intervention would provide new and relevant information. For example, people are motivated to avoid receiving information about charitable causes to have an excuse not to give (Exley and Petrie 2018) or they selectively seek and reinforce exposure to news outlets with politically aligned values, even when they are given other information from other sources (Garrett 2009). 
In short, the BBC model does not provide a checklist or a recipe of "ingredients to include" which always apply-instead, we offer a systematic approach to understanding what drives behaviour change, of which beliefs, barriers and contexts are common elements. However, a complete theory of behaviour change should, of course, recognise that behaviour is likely influenced by a myriad of factors, including but not limited to beliefs, structural barriers, context, available information, framing, cognitive limitations, and traditional economic considerations, such as prices and income effects.

\section{Conclusion}

We propose a complementary process to the typical design of behavioural nudges, which we hope will offer researchers, policy-makers and organizations guidance on how best to select and design relevant nudges for their population, problem, and context-rather than throw the kitchen sink of nudges at every problem. The BBC model we propose has three components - understanding beliefs, barriers, and context-which help identify what beliefs need to be budged in order for behaviour to be nudged.

Open Access This article is distributed under the terms of the Creative Commons Attribution 4.0 International License (http://creativecommons.org/licenses/by/4.0/), which permits unrestricted use, distribution, and reproduction in any medium, provided you give appropriate credit to the original author(s) and the source, provide a link to the Creative Commons license, and indicate if changes were made.

\section{References}

Aarts H, Verplanken B, van Knippenberg A (1998) Predicting behavior from actions in the past: repeated decision making or a matter of habit? J Appl Soc Psychol 28(15):1355-1374

Allcott H (2011) Social norms and energy conservation. J Public Econ 95(9-10):1082-1095. https://doi. org/10.1016/j.jpubeco.2011.03.003

Allcott H, Rogers T (2014) The short-run and long-run effects of behavioral interventions: experimental evidence from energy conservation. Am Econ Rev 104(10):3003-3037

Ariely D (2008) Predictably irrational: the hidden forces that shape our decisions. HarperCollins, New York City

Ariely D, Norton MI (2008) How actions create-not just reveal-preferences. Trends Cognit Sci 12(1):13-16. https://doi.org/10.1016/j.tics.2007.10.008

Barasz K, John LK, Keenan EA, Norton MI (2017) Pseudo-set framing. J Exp Psychol Gen 146(10):1460-1477. https://doi.org/10.1037/xge0000337

Benartzi S, Beshears J, Milkman KL, Sunstein CR, Thaler RH, Shankar M et al (2017) Should governments invest more in nudging? Psychol Sci 28(8):1041-1055

Bhanot SP (2017a) Cheap promises: evidence from loan repayment pledges in an online experiment. J Econ Behav Organ 140:246-266. https://doi.org/10.1016/j.jebo.2017.04.007

Bhanot SP (2017b) Rank and response: a field experiment on peer information and water use behavior. J Econ Psychol 62:155-172. https://doi.org/10.1016/j.joep.2017.06.011

Bohner G, Schlüter LE (2014) A room with a viewpoint revisited: descriptive norms and hotel guests' towel reuse behavior. PLoS ONE 9(8):e104086-e104087. https://doi.org/10.1371/journ al.pone.0104086

Cappelli P, Sherer PD (1991) The missing role of context in OB: the need for a meso-level approach. Res Organ Behav 13:55-110 
Chatman JA, Flynn FJ (2005) Full-cycle micro-organizational behavior research. Organ Sci 16(4):434447. https://doi.org/10.1287/orsc. 1050.0136

Chou EY (2015) What's in a name? The toll e-signatures take on individual honesty. J Exp Soc Psychol 61(C):84-95. https://doi.org/10.1016/j.jesp.2015.07.010

Cialdini RB (1987) Influence. vol 3. A. Michel, Port Harcourt

Cialdini RB, Trost MR (1998) Social influence: social norms, conformity and compliance. In: Gilbert DT, Fiske ST, Lindzey G (eds) The handbook of social psychology. McGraw-Hill, New York, NY, US, pp 151-192

Congdon WJ, Shankar M (2015) The white house social \& behavioral sciences team: lessons learned from year one. Behav Sci Policy 1(2):77-86

Dolan P, Hallsworth M, Halpern D, King D, Metcalfe R, Vlaev I (2012) Influencing behaviour: the mindspace way. J Econ Psychol 33(1):264-277. https://doi.org/10.1016/j.joep.2011.10.009

Exley CL, Petrie R (2018) The impact of a surprise donation ask. J Public Econ 158:152-167

Furnham A, Boo HC (2011) A literature review of the anchoring effect. J Soc Econ 40(1):35-42. https:// doi.org/10.1016/j.socec.2010.10.008

Garrett RK (2009) Politically motivated reinforcement seeking: reframing the selective exposure debate. J Commun 59(4):676-699. https://doi.org/10.1111/j.1460-2466.2009.01452.x

Gigerenzer G, Gaissmaier W (2011) Heuristic decision making. Ann Rev Psychol 62(1):451-482. https:// doi.org/10.1146/annurev-psych-120709-145346

Goldstein DG, Gigerenzer G (2002) Models of ecological rationality: the recognition heuristic. Psychol Rev 109(1):75-90. https://doi.org/10.1037//0033-295X.109.1.75

Goldstein NJ, Cialdini RB, Griskevicius V (2008) A room with a viewpoint: using social norms to motivate environmental conservation in hotels. J Consum Res 35(3):472-482. https://doi. org/10.1086/586910

Hallsworth M, Chadborn T, Sallis A, Sanders M, Berry D, Greaves F, Clements L, Davies SC (2016) Provision of social norm feedback to high prescribers of antibiotics in general practice: a pragmatic national randomised controlled trial. The Lancet 387:1-10. https://doi.org/10.1016/S0140 -6736(16)00215-4

Hallsworth M, List JA, Metcalfe RD, Vlaev I (2017) The behavioralist as tax collector: using natural field experiments to enhance tax compliance. J Public Econ 148:14-31. https://doi.org/10.1016/j.jpube co.2017.02.003

Halpern D (2015) Inside the nudge unit: how small changes can make a big difference. WH Allen, London

Hauser OP, Luca M (2015) How to design (and analyze) a business experiment. Harvard Bus Rev

Hauser OP, Norton MI (2017) (Mis)perceptions of inequality. Curr Opin Psychol 18:21-25. https://doi. org/10.1016/j.copsyc.2017.07.024

Hauser OP, Kraft-Todd GT, Rand DG, Nowak MA, Norton MI (2016) Invisible inequality leads to punishing the poor and rewarding the rich. In: Academy of management proceedings

Hauser OP, Linos E, Rogers T (2017) Innovation with field experiments: studying organizational behaviors in actual organizations. Res Organ Behav 37:185-198. https://doi.org/10.1016/j. riob.2017.10.004

Hauser OP, Greene M, DeCelles KA, Norton MI, Gino F (2018) Minority report: a modern perspective on reducing unethical behavior in organizations. In: Academy of management global proceedings

Haynes L, Goldacre B, Torgerson D (2012) Test, learn, adapt: developing public policy with randomised controlled trials. Cabinet office white paper. https://doi.org/10.2139/ssrn.2131581

Heller SB (2014) Summer jobs reduce violence among disadvantaged youth. Science 346(6214):12191223. https://doi.org/10.1126/science.1257809

Jachimowicz JM, Hauser OP, O'Brien JD, Sherman E, Galinsky AD (2018) The critical role of secondorder normative beliefs in predicting energy conservation. Nat Hum Behav 2:757-764. https://doi. org/10.1038/s41562-018-0434-0

Jachimowicz JM, Duncan S, Weber EU, Johnson EJ (2019) When and why defaults influence decisions: a meta-analysis of default effects. Behav Public Policy. https://doi.org/10.1017/bpp.2018.43

Johns G (2006) The essential impact of context on organizational behavior. Acad Manag Rev 31:386

Kahneman D (2011) Thinking, fast and slow. Farrar, Straus and Giroux, New York

Kettle S, Hernandez M, Sanders M, Hauser O, Ruda S (2017) Failure to CAPTCHA attention: null results from an honesty priming experiment in guatemala. Behav Sci 7:28. https://doi.org/10.3390/bs702 0028 
Kiatpongsan S, Norton MI (2014) How much (more) should CEOs make? A universal desire for more equal pay. Perspect Psychol Sci 9(6):587-593

Kuziemko I, Norton MI, Saez E, Stantcheva S (2015) How elastic are preferences for redistribution? evidence from randomized survey experiments. Am Econ Rev 105(4):1478-1508. https://doi. org/10.1257/aer.20130360

List J (2006) Field experiments: a bridge between lab and naturally occurring data. Adv Econ Anal Policy 6(2): $1-47$

Luca M, Hauser O (2016) Good Communication requires experimenting with your language. retrieved June 22, 2017. https://pdf.printfriendly.com/pdfs/make

Ludwig J, Kling JR, Mullainathan S (2011) Mechanism experiments and policy evaluations. J Econ Perspect 25(3):17-38

Milkman KL, Beshears J, Choi JJ, Laibson D, Madrian BC (2011) Using implementation intentions prompts to enhance influenza vaccination rates. Proc Natl Acad Sci 108(26):10415-10420. https:// doi.org/10.1073/pnas.1103170108/-/DCSupplemental

Mowday RT, Sutton RI (1993) Organizational behavior: linking individuals and groups to organizational contexts. Ann Rev Psychol 44:195-229

Norton MI, Ariely D (2011) Building a better America-one wealth quintile at a time. Perspect Psychol Sci 6(1):9-12

Podsakoff PM, Podsakoff NP (2018) Experimental designs in management and leadership research strengths, limitations, and recommendations for improving publishability. Leadersh Q 30:11-33. https://doi.org/10.1016/j.leaqua.2018.11.002

Rogers T, Ternovski J, Yoeli E (2016) Potential follow-up increases private contributions to public goods. In: Proceedings of the national academy of sciences, 201524899-8. http://doi.org/10.1073/ pnas. 1524899113

Schultz PW, Nolan JM, Cialdini RB (2007) The constructive, destructive, and reconstructive power of social norms. Psychol Sci 18(5):429-434

Shang J, Croson R (2009) A field experiment in charitable contribution: the impact of social information on the voluntary provision of public goods. Econ J 119(540):1422-1439. https://doi.org/10.111 1/j.1468-0297.2009.02267.x

Sheehy-Skeffington J, Kteily N, Hauser OP (2016) Antecedents and consequences of perceptions of economic inequality. In: Tobin project conference on inequality decision-making, paper presentation

Shu LL, Mazar N, Gino F, Ariely D, Bazerman MH (2012) Signing at the beginning makes ethics salient and decreases dishonest self-reports in comparison to signing at the end. Proc Natl Acad Sci 109(38):15197-15200. https://doi.org/10.1073/pnas.1209746109

Silva A, John P (2017) Social norms don't always work: an experiment to encourage more efficient fees collection for students. PLoS ONE 12(5):e0177354-e0177359. https://doi.org/10.1371/journ al.pone.0177354

Thaler RH, Sunstein CR (2008) Nudge: improving decisions about health, wealth, and happiness. Yale University Press, New Haven

The Behavioural Insights Team (2014) Four simple ways to apply behavioural insights. White Paper, pp $1-53$

The Behavioural Insights Team (2015) Update report 2013-2015. White Paper, pp 1-59

Verkooijen KT, Stok FM, Mollen S (2015) The power of regression to the mean: a social norm study revisited. Eur J Soc Psychol 45(4):417-425

Publisher's Note Springer Nature remains neutral with regard to jurisdictional claims in published maps and institutional affiliations. 